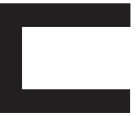

\title{
ESTUDO SOBRE O CAMPO REPRESENTACIONAL DO TURISMO EM PIRAMBU [SE]
}

Anderson Pereira Mendonça ${ }^{2}$
Natanael Reis Bomfim²

\section{RESUMO}

O potencial turístico do município de Pirambu, cidade litorânea do estado de Sergipe, tem se propagado pela mídia, pelo governo e pelas agências turísticas no estado, através de seus inúmeros recursos naturais, mas que de certa forma não encontra correspondência na infra-estrutura da cidade e nem no comportamento de seus moradores, no qual um jogo de forças se estabelece entre a população, o governo e os ambientalistas. 0 presente estudo objetivou compreender as Representações Sociais construídas pela comunidade local de Pirambu, acerca do lugar turístico, como forma de identificar elementos formadores de identidade sócio-territorial que podem servir de subsídios para elaboração de estratégias que orientem as práticas sociais para o desenvolvimento da atividade turística local. Nesse sentido, buscou-se o auxílio das ciências sociais, por meio das Representações Sociais, a fim de apreender o conteúdo cons- truído acerca do Turismo em Pirambu (SE). Para tal, realizou-se uma pesquisa a partir da associação livre de palavras, com a construção de um mapa cognitivo e interpretado através da frequência das palavras evocadas. As estruturas apreendidas nas associações de palavras, das Representações Sociais do Turismo em Pirambu, destacam o aspecto de indissociação entre Turismo, Belezas naturais e Cultura. Tais elementos constituem a identidade do local e a partir dessa identidade que os sujeitos vão estabelecendo relações e atribuindo significados às coisas, porém apesar de os atores reconhecerem o Turismo como uma alternativa viável para o desenvolvimento, os resultados apontam para a inexistência da atividade no local.

\section{PALAVRAS-CHAVE}

Representações Sociais. Cultura. Turismo. Pirambu. 


\section{ABSTRACT}

The tourism potential of the city of Pirambu seaside town in the state of Sergipe, has been propagated by the media, government and tourism agencies in the state, through its numerous natural resources, but that somehow does not find correspondence in infrastructure city nor the behavior of its inhabitants, in which a set of forces is established between the population, the government and environmentalists. The present study aimed to understand the social representations constructed by the local community Pirambu about tourist place, in order to identify elements forming socio-territorial identity that can contribute for the development of strategies that guide social practices for the development of local tourism. Accordingly, we sought the help of the social sciences, through social representations in order to grasp the content built about tourism in Pirambu (SE). To this end, we carried out a survey from the free association of words with the construction of a cognitive map and interpreted by the frequency of words evoked. The structures seized in word associations, social representations of tourism in Pirambu, highlight the aspect of indissociation between tourism, culture and natural beauties. These elements constitute the identity of the place and from this identity that subjects will establish relationships and assigning meanings to things, but even though the actors recognize tourism as a viable alternative to the development, the results point to the lack of activity on the site.

\section{KEYWORDS}

Social Representations. Culture. Tourism. Pirambu.

\section{RESUMEN}

El potencial turístico de la ciudad de Pirambu ciudad costera en el estado de Sergipe, se ha propagado por los medios de comunicación, del gobierno y de las agencias de turismo en el estado, y a través de sus numerosos recursos naturales, pero, que de alguna manera no encuentra correspondencia en infraestructura ciudad ni el comportamiento de sus habitantes, en la que se establece un conjunto de fuerzas entre la población, el gobierno y los ambientalistas. El presente estudio tuvo como objetivo comprender las representaciones sociales construidas por la comunidad local acerca de Pirambu, lugar turístico con el fin de identificar los elementos que constituyen la identidad socio-territorial que pueden contribuir al desarrollo de estrategias que orientan las prácticas sociales para el desarrollo de la actividad del turismo local. En consecuencia, se solicitó la ayuda de las ciencias sociales, a través de las representaciones sociales con el fin de sumar conocimiento respecto a al turismo de Pirambu (SE). Para ello, llevamos a cabo una encuesta de la asociación libre de palabras con la construcción de un mapa cognitivo e interpretada por la frecuencia de las palabras evocadas. Las estructuras incautadas en asociaciones de palabras, las representaciones sociales del turismo Pirambu, destacan el aspecto indisociable entre el turismo, la cultura y bellezas naturales. Estos elementos constituyen la identidad del otro y de esta identidad que los sujetos establecer relaciones y la asignación de significados a las cosas, pero, a pesar de que los actores reconocen el turismo como una alternativa viable para el desarrollo, los resultados apuntan a la falta de actividad en el sitio.

\section{PALABRAS CLAVE}

Representaciones Sociales. Cultura. Turismo. Pirambu. 


\section{INTRODUÇÃ̃O}

A presente pesquisa versa sobre as Representações Sociais que a comunidade local de Pirambu (SE) tem a respeito do Turismo. A atividade turística, sempre relacionada ao município de Pirambu, cidade litorânea do estado de Sergipe, propagada pelos diversos meios de comunicação, pelo governo e pelas agências de Turismo do estado, reconhecem o potencial turístico do município, por meio de seus inúmeros recursos naturais, o que de certo modo não encontra correspondência na estrutura da cidade e nem no comportamento de seus moradores. Desta forma, verifica-se um distanciamento da população com relação às ações nesse sentido ocorridas no local, muitas vezes impostas por gestores, sem consulta à população, bem como por ambientalistas do Projeto TAMAR (Programa Brasileiro de Conservação das Tartarugas Marinhas), o qual se configura como uma importante ferramenta para a divulgação do município e consequentemente, um atrativo para visitação.

\section{TERRITORIALIZAÇÃO E TURISMO EM PIRAMBU ISE}

O município de Pirambu está localizado no litoral sergipano, localizado a $28 \mathrm{~km}$ de distância da Capital, Aracaju, via Rodovia SE-100 e 76 km pela BR-101. Possui uma população de 8.369 habitantes conforme dados do último censo demográfico realizado pelo Instituto Brasileiro de Geografia e Estatística (IBGE, 2010).

O município configura-se também como um dos maiores centros pesqueiros de Sergipe. Ressaltando o aspecto ambiental, Pirambu conta ainda com a reserva biológica de Santa Izabel que influencia todo o processo de desenvolvimento do município. Criada pelo Decreto $N^{\circ}$ 96.999, de novembro de 1988, objetiva proteger as espécies de tartarugas marinhas que procuram esses sítios em intervalos regulares, durante a estação reprodutiva (FONSECA; VILAR; SANTOS, 2010).
Para compreender essas transformações, recorreu-se à Teoria das Representações Sociais, como teoria e método que na concepção de Moscovici (1976), configura-se como um conjunto de ideias, opiniões, valores, preconceitos e estereótipos que os indivíduos têm sobre um objeto social. Estes elementos são fomentadores da construção da identidade entre o sujeito e o objeto. Nesse contexto o Turismo em Pirambu é considerado como um objeto da Representação e reflete um saber que os indivíduos de uma dada sociedade ou de um grupo social elaboram e compartilham acerca da possibilidade ou não de sua existência.

Assim, o objetivo central do presente estudo foi identificar e analisar o conteúdo das representações sociais construídas pelos atores sociais do município de Pirambu, litoral norte do estado de Sergipe, no que se refere à existência ou não do Turismo no Local.

Situado dentro desta Reserva, Pirambu abriga a primeira base do Projeto TAMAR, instalada no Brasil em 1982. O Projeto Monitora $53 \mathrm{~km}$ de praias e protege quase 2.400 desovas e 106 mil filhotes, a cada temporada. Cerca de $80 \%$ desses filhotes são da espécie Lepidochelys Olivacea (Tartaruga Oliva), a menor entre as tartarugas marinhas que ocorrem no Brasil.

Embora o município seja reconhecido e sempre associado ao Turismo em Sergipe, o potencial e recursos turísticos não são formatados em oferta turística, entendida como o conjunto de equipamentos, bens e serviços que existem numa determinada região para usufruto dos turistas (OMT, 2006), já que esta não encontra correspondência na estrutura do município, mesmo que o Turismo seja encarado como uma alter- 
nativa de desenvolvimento, através da ampla divulgação do mesmo nos meios de comunicação como rádio, televisão, jornais, revistas, sites, guias informativos, feiras nacionais e internacionais, devido às suas belezas naturais.

As propagadas, incentivadas pela mídia, equivalem a imagem do Município a um "paraíso", "eldorado", "santuário ecológico". Um dos principais desafios para Pirambu é o de incentivar o crescimento da atividade turística, conciliando-a com a conservação do equilíbrio socioambiental e cultural da região. Para isso, torna-se imprescindível que as intervenções se façam de forma planejada, compatível com a capacidade de suporte, com a participação das comunidades envolvidas e, como alerta Avila (2009), adequando-se aos princípios de sustentabilidade. Logo, o tratamento econômico do Turismo requer, no entanto, uma abordagem que contemple ao lado da análise científica, a consideração do elemento humano, que é fundamental em sua manifestação.

Portanto, entender os processos psicossociais desencadeados pelo fenômeno turístico, as expectativas, os desejos, satisfações e frustrações de comunidades locais, turistas e visitantes, a dinâmica cultural em que o Turismo está inserido, possam ser o fermento para o planejamento equilibrado de um Turismo mais responsável.

\section{A TEORIA DAS REPRESENTACÕES SOCIAIS COMO MÉTODO DE PESQUISA}

Para analisar o conteúdo das Representações Sociais sobre os o Turismo em Pirambu (SE), recorreu-se a teoria e método das Representações Sociais (TRS), definida por Moscovici (1976) como um conjunto de ideias, opiniões, valores, preconceitos e estereótipos que os sujeitos têm sobre um objeto social. Compreender o Turismo como Fenômeno Social, exige antes de tudo entender que o conhecimento científico se processa a partir da relação entre os sujeitos e o objeto, a partir dos níveis de experiências que esses travam nesta relação. Isso significa dizer que o conhecimento empírico desenvolvido, a partir de suas experiências com o fenômeno no espaço vivido, tem uma importância fundamental para a construção da ciência. Essa, por sua vez, apresenta um arcabouço teórico e metodológico que permite a sua evolução epistemológica, contribuindo não só com o seu avanço, mas também na sua intervenção social.

O estudo das Representações Sociais se constitui como um grande campo de investigação em diferen- tes abordagens nas Ciências Sociais e Humanas (JODELET, 1989). Nesse contexto, Bomfim (2005) apud Souza (2008), entende que nas Ciências Humanas e Sociais, os estudos sobre as Representações Sociais ocupam um lugar importante e buscam explicar a relação entre as produções mentais e as dimensões materiais e funcionais da vida dos grupos, acrescentando ainda que a Representação Social é parte do cotidiano e um produto da comunicação e da linguagem, constituindo-se numa organização de imagens. Logo, a TRS enfatiza e simboliza atos e situações cujo uso os torna comum. Sendo, portanto, uma modalidade particular do conhecimento, que tem por função a elaboração de comportamentos e a comunicação entre indivíduos.

O termo Representações Sociais se originou através do conceito de Representações Coletivas de Durkheim (1963), de modo que a teoria pode ser caracterizada como um campo multidisciplinar ou interdisciplinar, a partir do momento em que foi influenciada e recebeu contribuições de outras áreas das 
Ciências Sociais, como a Antropologia, a Sociologia a Geografia e, sobretudo a Psicologia Social.

Para Moscovici (1976), a TRS se configura como um conjunto de ideias, opiniões, valores, preconceitos e estereótipos que os indivíduos têm sobre um objeto social. 0 autor introduz, em sua teoria, uma noção de sujeito ativo e construtor, assim, é importante destacar que o conceito de Representação Social parte da proposição de consciência coletiva, porém não relaciona indivíduo e sociedade de forma dicotômica. Desse modo, o homem não absorve os conteúdos que a sociedade o impõe, ele os reformula, na medida em que é um ser ativo e não passivo diante do mundo. Em síntese, o autor se interessou não apenas em compreender como o conhecimento é produzido, mas principalmente em analisar seu impacto nas práticas sociais e vice-versa.

A TRS estrutura-se a partir da construção de conhecimentos socialmente compartilhados e, consequentemente às cognições. A dimensão simbólica e o caráter imaginativo a respeito desses conhecimentos refletem a dimensão dos afetos, porque quando os atores sociais empenham-se em compreender e representar o mundo, eles também se utilizam de emoção e sentimento (GUARESCHI; JOVCHELOVITCH, 1995).

Portanto, a utilização da abordagem estrutural da TRS torna-se de grande valia para organização dos conteúdos (ABRIC, 1998; CHAVES; SILVA, 2011). Tal abordagem organiza as representações como um conjunto estruturado e hierarquizado de elementos, apresentando uma lógica adequada.

No caso da presente pesquisa, destacam-se os processos culturais e o turismo no município de Pirambu (SE). Ou seja, se por um lado espera-se entender as Representações Sociais sobre o Turismo, por outro se torna possível apreender a dinâmica social e cultural do lugar e seus processos individuais e coletivos.

Para tanto, considera-se que as Representações Sociais como produto e processo estruturam-se em duas instâncias principais: um núcleo central, mais resistente a mudanças, sendo a base comum propriamente social e coletiva, que segundo Abric (1998), se constitui como elemento fundamental da representação, pois é ele que determina ao mesmo tempo, sua significação e sua organização interna e uma periférica, mais maleável e disposta a se modificar, no intuito de englobar eventos, ideias e objetos que sejam contraditórios a priori para, ao interagir com o novo, integrá-lo na representação pré-existente ou criar uma nova representação a partir desta inovação, sendo mais associada às características individuais e ao contexto imediato e contingente nos quais os indivíduos estão inseridos (ABRIC, 1998; OLSCHOWSKY, 2007).

Tal movimento pode parecer contraditório, mas é essencial no processo, destacando que uma representação só se transforma a partir do momento em que o próprio núcleo central é transformado. Portanto entende-se que o sistema central é estável, coerente, consensual e historicamente definido, enquanto que o sistema periférico constitui o complemento indispensável do sistema central do qual ele depende, isto porque se o sistema central é essencialmente normativo, o sistema periférico, é, por sua vez, funcional. Devido a ele, a representação pode se ancorar na realidade do momento (ABRIC, 1998).

Para explicar o processo de formação das Representações, Moscovici (1978) salienta dois aspectos importantes: ancoragem e objetivação. A objetivação torna concreto aquilo que é abstrato, transformando um conceito em imagens, retirando-o de seu marco conceitual científico. Trata-se de privilegiar certas informações em detrimento de outras, simplificando-as e dissociando-as de seu contexto original de produção (ALMEIDA; SANTOS, 2011). Portanto, como salienta o próprio Moscovici (2003) apud Chaves e Silva (2011, p. 311), "objetivar é reproduzir um conhecimento em uma imagem até que essa imagem se converta num elemento da realidade, ao invés de ser apenas um elemento do pensamento", pois segundo o autor, ao objetivar algo, se preenche a defasagem entre a representação e o que ela representa. 
Já a ancoragem se refere ao fato de tudo o que se pensa sobre alguma coisa ter um embasamento na realidade. Quando se pensa sobre um objeto, o sujeito usa como referência experiências e esquemas de pensamento já estabelecidos. Desse modo, a ancoragem assemelha-se a um processo de categorização, uma vez que atribui aos objetos um local dentro de uma malha de significados (VALA, 1996; MOSCOVICI, 1978). Permite, portanto, integrar o objeto da representação em um sistema de valores próprios aos indi- víduos, denominando-o e classificando-o em função da inserção social dos mesmos.

Ressalta-se que o Turismo enquanto fenômeno social, gerador de múltiplas inter-relações de importância social, econômica e cultural, torna-se um campo rico para ser enfocado a partir da perspectiva das Representações Sociais, pois o mesmo propicia experiências psicológicas e culturais aos envolvidos, foco principal da presente pesquisa.

\section{METODOLOGIA}

0 corpus dessa pesquisa tem sua análise no mapa cognitivo, advindo da evocação livre de palavras e do discurso elaborado pelos sujeitos. Para tal foi captado e analisado o sistema categorial, através das palavras mais frequentes, com a finalidade de isolar o conteúdo da Representação Social, elaborando um mapa cognitivo. Esse mapa pode ser entendido ainda, como conceitual ou mental, e definido como uma ferramen- ta metodológica utilizada nos estudos e pesquisas em Psicologia Social (SERPA, 2005). O mapa cognitivo sobre o Turismo em Pirambu (SE) resultou da frequência de palavras evocadas durante o recolhimento dos dados. 0 mapa foi analisado e interpretado destacando as representações sociais sobre o objeto de estudo, nesse caso, a existência do Turismo em Pirambu.

Para a criação do mapa conceitual sobre Turismo (Figura, 1), verificou-se que as palavras que aparecem com maior destaque para o núcleo central são: lazer (215), festa (168), estrutura (121), renda (93) e praia (90).

Em primeira análise, percebe-se uma imagem de dois segmentos do Turismo. De lazer (125) e de sol e praia (90). Isto significa que a Representação Social desses atores, é construída a partir de uma ideia e uma opinião sobre o Turismo influenciada pelo marketing do Estado de Sergipe. 


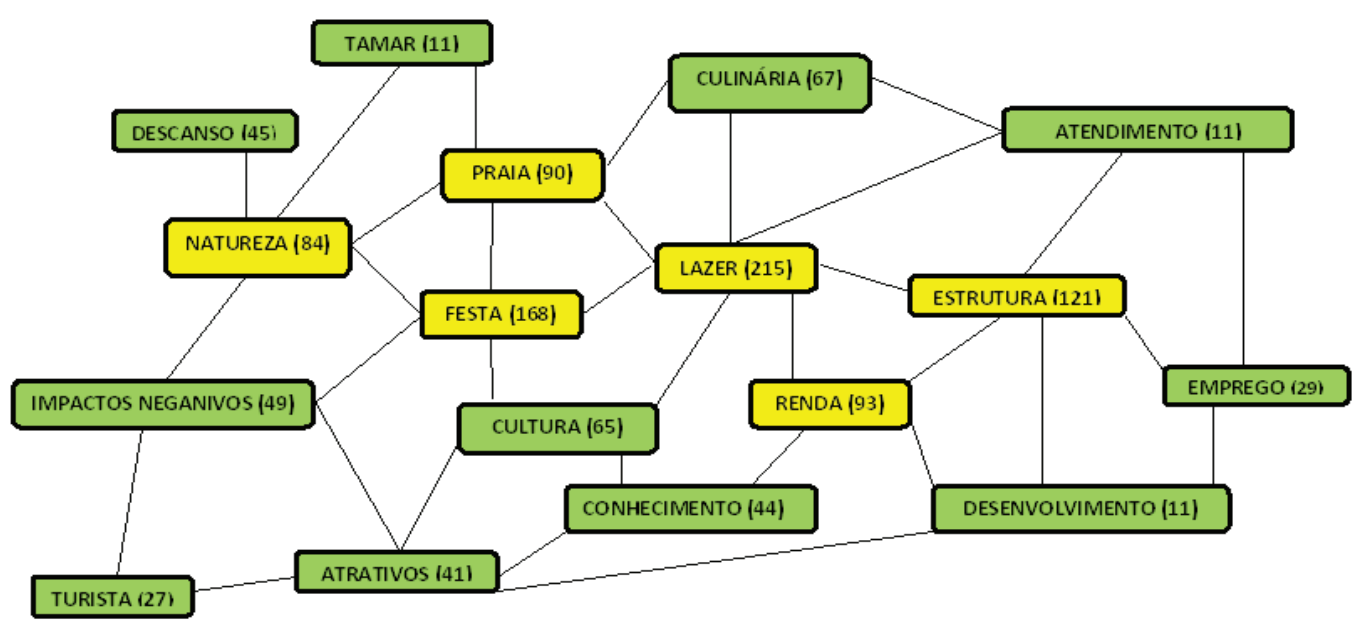

\section{\begin{tabular}{|c|}
\hline NÚCLEO CENTRAL \\
\hline ELEMENTOS PERIFÉRICOS
\end{tabular}}

Figura 1. Mapa Conceitual das Representações Sociais acerca do Turismo Fonte: Elaboração do Autor (2012)

Em contrapartida, os participantes reconhecem o Turismo como uma atividade econômica capaz de emprego (29) e renda (93), mesmo que o lugar ainda não apresente uma infraestrutura para tal (atendimento 11), bem como a presença do Projeto TAMAR (11).

Por outro lado, a festa (168) se evidencia como um elemento identitário da cultura (65) e do lugar pela sua natureza (84), tranquilidade que pode propiciar o descanso (45) para o turista (27), bem como, sua culinária (67), visto que o município sempre se destacou no cenário estadual pelas manifestações culturais que fazem parte do calendário de eventos e se apresentam, segundo eles, como atrativos (41) e oportunidade de conhecimento (44), tais que: Carnaval, Culturarte, Festa da Padroeira Nossa Senhora de Lurdes com a guerra das cabacinhas. Apesar de esses atrativos serem potenciais para um possível desenvolvimento (11) da prática do Turismo, fica evidente para a comunidade, que essa prática pode gerar impactos negativos (49) para o lugar.
A imagem do Turismo construída pelos pirambuenses está inserida numa crença coletiva de uma possibilidade de transformação do espaço natural e cultural em um lugar turístico, otimizando as relações sociais e econômicas. Portanto, a Representação Social do Turismo em Pirambu, construída pelos atores sociais e revelada pelo seu conteúdo, implica numa imagem tanto positiva como negativa, que se apresenta como um campo de forças entre uma representação de Turismo veiculada pelo marketing para o estado e aquela idealizada pelos atores sociais e evidenciada por meio de crenças coletivas.

Para Bordieu (1989) um campo de forças pode ser definido como um espaço social onde os agentes que estão situados concorrem e disputam relações de poder. Isto significa dizer que, os atores sociais de Pirambu ocupam posições relativas nesse espaço de relações e travam embates, cada qual com possibilidades diferenciadas sobre o mundo material e simbólico. Assim, os conflitos ambientais, políticos, ideológicos, sociais e culturais tornam-se o foco desse 
trabalho, pois, deste ponto de vista, toma-se o campo de forças e o campo simbólico como centro para as disputas de significados e representações sociais do Turismo em Pirambu.

Quando a representação destaca essa realidade, percebe-se então uma noção de conflito e luta simbólica que é explicado por Oliveira (2004), quando a autora busca analisar o campo ambiental, aqui o lugar, num jogo de relações entre o campo de luta política e de significações. Essas relações são caracterizadas pelo jurídico e político definido por Bordieu (1989) como o espaço social de diferenciações onde são travadas as lutas de poder e as lutas simbólicas, das quais os atores sociais se esforçam para manter ou transformar a estrutura das relações existentes, legitimando ou não, práticas sociais e culturais.

\section{CONSIDERACÕ̃ES FINAIS}

Os atrativos turísticos que compõem a região na qual está inserido o município de Pirambu apresentam enorme potencial para o desenvolvimento de segmentos turísticos relacionados, em especial, o Turismo de Sol e Praia. Este potencial é reconhecido pela comunidade e pode ser verificado a partir de associações com suas belezas naturais tais como Praia, Mar, lagoas, dunas, cachoeira entre outros, as quais emergem na estrutura das representações. Além das belezas naturais, a comunidade destaca a cultura do local, a partir de suas manifestações, como um elemento importante, sobretudo as festas como o carnaval, que é considerado a principal festa do local. Apesar disso, tais manifestações têm sido planejadas para o público externo sem uma consulta interna, o que gera uma indiferença na comunidade local.

Isso leva a crer que estes elementos são formadores de uma identidade coletiva e sócio-territorial da comunidade, sendo a partir dela que as relações vão
Bomfim (2005) citado por Souza (2008) explica que os estudos sobre as Representações Sociais buscam explicar a relação entre as produções mentais e as dimensões materiais e funcionais da vida dos grupos. Nesse contexto, a Representação Social é parte do cotidiano dos pirambuenses, constituindo-se como um produto da comunicação e da linguagem que se organiza em imagens.

A Representação Social do Turismo em Pirambu se constitui como um produto organizado em temas, em conteúdo e discurso da realidade social e espacial. Lembrando que neste estudo, buscou-se apenas identificar o conteúdo ou produto das Representações, construído sobre o Turismo em Pirambu (SE).

se estabelecendo nesse espaço e os indivíduos vão atribuindo significados às coisas.

No que se refere ao Turismo, os dados mostram que a comunidade tem conhecimento do que seja a atividade, bem como os aspectos positivos e negativos que a envolve. A compreensão do Turismo entendido pela população se mostra estereotipado, pois tal segmento se apresenta de maneira mais generalizada por todo estado sem levar em consideração as particularidades do local.

Portanto, pode-se afirmar que, mesmo reconhecendo grande potencial para alguns segmentos, o Turismo de modo geral inexiste no município, mas evidencia-se que o visitante sim, esse faz parte da realidade do município e mesmo assim a relação com a população desse indivíduo é muito pequena.

Para fomentar uma sustentabilidade nesse lugar turístico, com atrativos que nem sempre atendem aos 
anseios da comunidade local, faz-se necessária a valorização de aspectos culturais como forma de desenvolver produtos turísticos que possibilitem o desenvolvimento do lugar.

Logo, torna-se evidente que Pirambu ainda está longe de ser destacado como um lugar turístico, porém de acordo com as representações construídas e compartilhadas pela comunidade, a esperança ganha destaque como um elemento consistente, mas para que isso aconteça é imprescindível um planejamento que envolva todos os atores sociais, já que este não pode prescindir de uma mudança nas representações do homem sobre si mesmo. Nesse contexto, este estudo possibilita o apontamento pragmático de subsídios que visem dar visibilidade interna às manifestações culturais do município resgatando o interesse do pirambuense pela manutenção da cultura.

Por fim, esse estudo não teve a pretensão de esgotar os debates em torno do tema. Destaca-se a necessidade de novos estudos, que promovam outros olhares e percepções sobre o Fenômeno do Turismo em Pirambu (SE).

\section{REFERÊNCIAS}

ABRIC, J. C. A abordagem estrutural das representações sociais. In MOREIRA, A. S. P.; OLIVEIRA, D. C. (Orgs). Estudos interdisciplinares de representação social (pp. 27-38). Goiânia: AB, 1998.

ALMEIDA, A. M. O.;SANTOS, M. F. S, A teoria das Representações Sociais. In: TORRES, C. V.; NEIVA, E.R. Psicologia Social: principais temas e vertentes. Porto Alegre: Artmed, 2011.

ÁVILA, M. A. Política e planejamento em cultura e turismo: reflexões, conceitos e sustentabilidade. In: ÁVILA, M. A. (Org.). Política e Planejamento em cultura e turismo. Ilhéus: Editus, 2009

BOMFIM, N. R. O conceito de patrimônio numa perspectiva multidisciplinar : contribuições para uma mudança de enfoque. Revista Turismo \& Desenvolvimento. São Paulo, vol. 5, n.1, p. 27-35, 2005

BORDIEU P. 0 poder Simbólico. Ed. Bertrand Brasil, Rio de Janeiro, 1989.

CHAVES, A. M. ;SILVA, P. L. Representações Sociais. In: CAMINO, L.; TORRES, A. R. R.; LIMA, M. E. O.; PEREIRA, M. E. (Org.). Psicologia Social: temas e teorias. 1 ed. Brasília, DF.: TechnoPolitik, 2011.

DURKHEIM, É. Sociologie et philosophie. Paris: PUF, 1963.

FONSECA, V. VILAR, J. W. C. e SANTOS, M. A. N. Reestruturação Territorial do Litoral de Sergipe. In VILAR, J. W. C e ARAUJO, H. M. Território, Meio Ambiente e Turismo no Litoral Sergipano. São Cristóvão: Editora UFS, 2010.

GUARESCHI, P. A.; JOVCHELOVITCH, S. Introdução. In: GUARESCHI, P. A.; JOVCHELOVITCH, S. Textos em Representações Sociais. 2. ed. Petrópolis, RJ: Vozes, 1995. 
INSTITUTO BRASILEIRO DE GEOGRAFIA E ESTATístICA (IBGE). Censo Demográfico. Brasília, 2010.

JODELET, D. Les représentations sociales: um domaine em expansion. In JODELET, D. (Org.). Les représentations sociales (pp. 31-61). Paris: PUF, 1989.

JOVCHELOVITCH, S. Vivendo a Vida com os Outros: Intersubjetividade, Espaço Público e Representações Sociais. In: GUARESCHI, P; JOVCHELOVITCH, S.(Org.). Textos em Representações Sociais. Petrópolis, RJ: Vozes, 2003.

MOSCOVICI, S. A representação social da psicanálise. Rio de Janeiro: Zahar, 1978.

MOSCOVICI, S. La Psychanalyse son image et son public. Paris: PUF, 1976.

OLIVEIRA, S. M. M. C. Conflitos Ambientais e Lutas simbólicas VIII Congresso Luso Afro-Brasileiro de Ciências Sociais, Coimbra, 2004.

OLSCHOWSKY, J. C. Mulheres na Ciência: Representação ou Fiç̧ão. Tese de Doutorado. Escola de Comunicações e Artes da USP. Ano de obtenção: 2007.

OMT. Introdução a Metodologia da Pesquisa em Turismo. São Paulo: Roca, 2006.

PROJETO TAMAR. Disponível em: http://www.tamar.org.br/interna.php?cod=36. Acesso em 10 jun. 2010.

SERPA, A. Por uma geografia das representações sociais. OLAM. Ciência \& Tecnologia. Rio Claro, SP. V. 5, N. 1. p.220-232. 2005..

SOUZA, M. L. M. As Representações Sociais da comunidade sobre elementos culturais e turísticos da Vesperata em Diamantina - MG. Dissertação (Mestrado em Cultura e Turismo) Universidade Estadual de Santa Cruz. Ilhéus, 2008.

VALA, J. Representações sociais: para uma psicologia social do pensamento social. In VALA, J.; MONTEIRO, M. B. Psicologia social. Lisboa: Fundação Calouste Gulbenkian, 1996. Santa Cruz/BA. anderson.p.mendonca@hotmail.com

Aceito em: 6 de julho de 2013

2 Doutor em Educação pela Université du Québec à Montréal. Pós-doutor em Geografia Humana pela Universidade de Paris I, Panthéon-Sorbonne, França. Professor Titular da Universidade do Estado da Bahia, UNEB. nabom_reis@hotmail.com 